\title{
Barriers and Facilitators of Colorectal Cancer Screening in a Federally Qualified Health Center (FQHC)
}

\author{
Kelly R. Ylitalo, PhD, Brendan G. Camp, MPH, M. Renée Umstattd Meyer, PhD, MCHES, \\ Lauren A. Barron, MD, Gabriel Benavidez, BS, Burritt Hess, MD, \\ Ryan Laschober, MD, and Jackson O. Griggs, MD
}

Introduction: Colorectal cancer is a leading cause of cancer-related mortality in the United States. Current screening recommendations for individuals aged 50 to 75 years include colonoscopy every 10 years, flexible sigmoidoscopy every 5 years, or annual stool-based testing. Stool-based testing, including fecal immunochemical tests (FITs), are cost effective, easy to perform at home, and noninvasive, yet many patients fail to return testing kits and go unscreened. The purpose of the study was to identify patient characteristics and perceived barriers and facilitators of FIT return.

Methods: Patients in a large, federally qualified health center who received a FIT kit order between January 1 and July 1, 2017 were identified. We compared sociodemographic and health characteristics between patients who returned and did not return FITs. We used telephone surveys to nonreturners to identify potential barriers (cost, knowledge, psychosocial factors) and facilitators (prepaid postage, outreach) of FIT kit return. An online survey of clinicians assessed perceived patient barriers and facilitators of colorectal cancer screening.

Results: Of the 875 patients who received a FIT order, 435 (49.7\%) did not return the kit and 121 of the nonreturners completed a telephone survey. Current smokers had an increased risk of FIT nonreturn compared with never smokers $(R R=1.32 ; 95 \% \mathrm{CI}, 1.13-1.54)$. Forgetfulness and lack of motivation were the most common FIT return barriers perceived by both patients and clinicians. Prepaid postage with return address on FIT return envelopes and live call reminders were the most commonly reported facilitators. Barriers and facilitators varied greatest between English- and Spanish-speaking patients.

Conclusion: In this study, the most common perceived barriers to return of screening fecal test kits were forgetfulness and lack of motivation. The most common perceived facilitators were live call reminders and postage-paid return envelopes. Understanding barriers and facilitators to FITs may be necessary to enhance cancer screening rates in underserved patient populations. ( $\mathrm{J}$ Am Board Fam Med 2019;32:180-190.)

Keywords: Colonoscopy, Colorectal Cancer, Early Detection of Cancer, Motivation, Occult Blood, Primary Health Care, Sigmoidoscopy, Vulnerable Populations

Colorectal cancer is the second most common type of cancer-related death in men and the third most common in women; over 50,000 deaths a year in

This article was externally peer reviewed.

Submitted 20 July 2018; revised 28 November 2018; accepted 28 November 2018.

From the Department of Public Health, Robbins College of Health and Human Sciences, Baylor University, Waco, TX (KRY, BGC, MRUM, GB); Medical Humanities Program, College of Arts and Sciences, Baylor University, the United States are attributable to colorectal cancer. ${ }^{1}$ Although substantial progress was made over the past 2 decades and colorectal cancer death rates

Waco (LAB); Family Health Center, Waco (BH, RL, JOG).

Funding: none.

Conflict of interest: none declared.

Corresponding author: Kelly R. Ylitalo, PhD, Department of Public Health, Robbins College of Health and Human Sciences, Baylor University, One Bear Place \#97343, Waco, TX 76798 (E-mail: kelly_ylitalo@baylor.edu). 
decreased by $34 \%$ among individuals $\geq 50$ years, ${ }^{1}$ gains have not been experienced equitably. Colorectal cancer deaths rates among non-Hispanic blacks are presently $40 \%$ higher than death rates among non-Hispanic whites, and Hispanics are the least likely race/ethnic group to be screened for colorectal cancer. ${ }^{1,2}$

The United States Preventive Services Task Force (USPSTF) recommends that healthy adults begin colorectal cancer screening at age 50 years and continue until at least age 75 years, at varying intervals depending on the screening test. ${ }^{3}$ Screening methods can include direct visualization tests such as colonoscopy every 10 years or flexible sigmoidoscopy every 5 years, or more frequent stoolbased tests such as annual guaiac fecal occult blood tests (gFOBTs) or annual fecal immunochemical tests (FITs). ${ }^{3}$ Although USPSTF recommendations indicate no preference for colorectal cancer screening method, ${ }^{3}$ physicians overwhelmingly prefer to recommend colonoscopies. ${ }^{4-8}$ This is particularly problematic for underserved patients because the high cost, intensive time preparation, and invasive nature of colonoscopies are common barriers to participation. ${ }^{9}$

Recent estimates suggest that only $61 \%$ of adults age $\geq 50$ years were up to date with colorectal cancer screening in $2015,{ }^{10}$ which falls short of the $70.5 \%$ goal of Healthy People 2020 national objectives. ${ }^{11}$ Low-income patients, particularly those served by federally qualified health centers, have the lowest colorectal cancer screening rates in the nation. Nationally, only $38.3 \%$ of federally qualified health center patients are screened ${ }^{12}$ and thus represent a priority population for colorectal cancer prevention. Stool-based tests, such as the FIT, are low cost, noninvasive, and simple, which may be more amenable for hard-to-reach patient populations. Recent work has shown that FIT participation is associated with older age, female sex, and higher socioeconomic status, ${ }^{13}$ but considerably less is known about low-income patients. The purpose of the study was to identify patients at a federally qualified health center who received a FIT order, compare patient characteristics between those who returned and did not return the FIT, and describe barriers and potential facilitators of future FIT participation. The secondary purpose of the study was to identify clinician perceptions of patient barriers and facilitators and colorectal cancer screening recommendations.

\section{Methods}

Our study was conducted in a large, multi-site federally qualified health center located in central Texas. The Waco Family Health Center provides care for over 58,000 unique patients, or approximately 1 in every 5 county residents, over $90 \%$ of whom live at or below $200 \%$ of the federal poverty guidelines. ${ }^{14}$ One quarter of patients are non-Hispanic black/African American, 40\% are Hispanic/ Latino, and 30\% are non-Hispanic white. ${ }^{14}$ Approximately 1 in 6 patients do not have health insurance and are afforded care through a sliding scale discounted fee program that expands coverage to approximately 1 quarter of self-pay patients. ${ }^{14}$ In 2016, 165,784 primary medical care encounters were provided by 68 physicians (21 family physicians, 38 resident/fellow family physicians, 2 pediatricians, 3 internists, 4 obstetrician/gynecologists), 14 nurse practitioners, and 5 physician assistants. ${ }^{14}$

From January 1, 2017 to July 1, 2017, 8717 patients aged 50 to 75 years without a history of colon cancer had a clinic visit at the Waco Family Health Center. Of those, 2473 (28\%) met USPSTF colorectal cancer screening recommendations by any screening method. The electronic health record system, Epic, was used to query all patient visits during which a FIT order was placed during this time period. The follow-up status of the FIT order was used to define screening adherence. Completed orders included FIT results from home-test kits that were returned for analysis; patients who returned the FIT were defined as screened and adherent to recommendations. Blank orders indicated that patients did not return the FIT kit; patients who had not returned the FIT were defined as nonadherent with USPSTF screening recommendations. In total, there were 1489 FIT orders between January 1 and July 1, 2017. After removing duplicates, patients younger than 50 years, and those with incomplete data, the final analytic sample included 875 nonduplicate patients aged $\geq 50$ years.

In addition to FIT screening completion, patient sociodemographic variables were obtained from the health record. Age in years was categorized as 50 to 59 years, 60 to 69 years, and 70 years or older. Sex was defined as female or male. Race/ ethnicity was defined as Hispanic or Latino, nonHispanic white, non-Hispanic black, or non-His- 
panic other. Patient insurance status was described as private insurance, public insurance, or self pay. Private insurance included commercial options (Blue Cross Blue Shield, Humana, United, etc.) and public insurance included Medicare and Medicaid. Self pay included patients without insurance and those covered by the sliding-scale discount fee program, nonprofit organizations, and other regional grant funding that provides subsidized care at the clinic. Body mass index (BMI) and smoking were also included as covariates because of documented associations with colorectal cancer screening. ${ }^{15,16}$ BMI was calculated using weight in kilograms $(\mathrm{kg})$ and height in meters $(\mathrm{m})$ from the health record and categorized as underweight or normal $\left(<25 \mathrm{~kg} / \mathrm{m}^{2}\right)$, overweight $(\geq 25$ and $<30$ $\left.\mathrm{kg} / \mathrm{m}^{2}\right)$, or obese $\left(\geq 30 \mathrm{~kg} / \mathrm{m}^{2}\right)$. Smoking status was defined as never smoker, former smoker, or current smoker.

Patients who did not return the FIT were contacted via telephone and provided information about participation in a survey in English or in Spanish, based on their language preference. Interviewers followed a script to obtain verbal informed consent from patients, which was approved by the Baylor University Institutional Review Board (IRB Reference \#1125461). As part of survey development, potential barriers and facilitators of colorectal cancer screening were identified using empirically supported barriers in the literature as well as those identified by administrators at our health center. Potential barriers included cost, ${ }^{17}$ time, ${ }^{18}$ poor/confusing instructional materials, ${ }^{17}$ transportation to FIT return sites, ${ }^{19}$ limited drop-off sites or return site hours of operation (recommended by local clinic administrators), fear of abnormal findings, ${ }^{17,20}$ embarrassment, ${ }^{21}$ lack of motivation, ${ }^{21}$ and forgetfulness. ${ }^{18}$ Potential facilitators included a prepaid postage with proper return address ${ }^{22}$; more drop-off sites (recommended by local clinic administrators); reminders by phone, email, text, or mail $^{19}$; better test instructions ${ }^{23}$; additional colorectal cancer screening educational materials ${ }^{17}$; or more time spent with the clinician. ${ }^{17}$ Patient participants were asked to respond with yes, no, or prefer not to answer to each barrier and facilitator. In addition, 2 open-ended questions accounted for unidentified barriers and facilitators (eg, what about the FIT process was difficult for you?, what would help you return the FIT in the future?). All responses were recorded in Microsoft Excel. Patients were called up to 6 times; of the 435 patients who did not return the FIT, 121 (28\%) participated in the telephone survey.

Eighty-seven clinicians, including physicians, resident/fellow physicians, physician assistants, and nurse practitioners, were sent an online invitation by an administrator at our health center to complete a survey using Qualtrics software. The clinician survey evaluated perceptions of patient barriers and facilitators related to colorectal cancer screening and their preferred colorectal cancer screening test based on patient's insurance status (colonoscopy, flexible sigmoidoscopy, fecal occult blood tests [FOBT]/FIT, other), adapted from previous literature. ${ }^{4,24-26}$ The clinician survey included the same FIT-related barriers and facilitators as the patient telephone survey. Provider preference for colorectal cancer screening test was measured by choosing 1 screening option for insured and 1 option for uninsured patients (colonoscopy, FIT, gFOBT, flexible sigmoidoscopy, patient preference, no preference, none of these). Thirty-one clinicians $36 \%$ of the 87 who were invited) participated in the survey.

Statistical analyses were performed using SAS v9.4 (SAS Institute Inc., Cary, NC). Descriptive statistics, including frequencies, means, and proportions, were generated for all study variables in the total sample. $\chi^{2}$ statistics were used to compare patients who did and did not return FITs. Logbinomial regression was conducted using the GENMOD procedure to estimate risk ratios and corresponding $95 \%$ confidence intervals ${ }^{27}$ for FIT nonreturn compared with FIT return. Bivariate models estimated the risk of FIT nonreturn for each patient characteristic separately and multivariate models included all covariates in a single model. Finally, frequencies and proportions were used to identify the most common barriers and facilitators to FIT return identified by patients and by clinicians. We compared patient-reported barriers by insurance status, race/ethnicity, and language preference using Fisher's exact test. Statistical significance was 2 -sided and defined at the $\alpha=$ 0.05 level.

\section{Results}

Patients age $\geq 50$ years of age who received a FIT order between January 1, 2017 and July 1, 2017 are described in Table 1. Approximately two thirds 
Table 1. Patient Characteristics of Total Sample and by FIT Return Status, $\mathbf{n}=\mathbf{8 7 5}$

\begin{tabular}{|c|c|c|c|c|}
\hline & $\begin{array}{c}\text { Total } \\
(\mathrm{n}=875)\end{array}$ & $\begin{array}{l}\text { FIT Return } \\
(\mathrm{n}=440)\end{array}$ & $\begin{array}{l}\text { FIT Non-Return } \\
\quad(\mathrm{n}=435)\end{array}$ & $P$ \\
\hline Sex, n (\%) & & & & .33 \\
\hline Male & $322(36.8)$ & $155(35.2)$ & $167(38.4)$ & \\
\hline Female & $553(63.2)$ & $285(64.8)$ & $268(61.6)$ & \\
\hline Age, n (\%) & & & & .19 \\
\hline 50 to 59 years & $478(54.6)$ & $227(51.6)$ & $251(57.7)$ & \\
\hline 60 to 69 years & $327(37.4)$ & $176(40.0)$ & $151(34.7)$ & \\
\hline 70 years and older & $70(8.0)$ & $37(8.4)$ & $33(7.6)$ & \\
\hline Race/Ethnicity, n (\%) & & & & .02 \\
\hline Hispanic or Latino & $392(44.8)$ & $213(48.4)$ & $179(41.2)$ & \\
\hline Non-Hispanic white & $259(29.6)$ & $133(30.2)$ & $126(29.0)$ & \\
\hline Non-Hispanic black & $213(24.3)$ & $91(20.7)$ & $122(28.1)$ & \\
\hline Non-Hispanic other & $11(1.3)$ & $3(0.7)$ & $8(1.8)$ & \\
\hline Insurance Status, n (\%) & & & & .07 \\
\hline Private & $246(28.1)$ & $131(29.8)$ & $115(26.4)$ & \\
\hline Public & $214(24.5)$ & $93(21.1)$ & $121(27.8)$ & \\
\hline Self-pay & $415(47.4)$ & $216(49.1)$ & $199(45.8)$ & \\
\hline Body mass index, $\mathrm{n}(\%)$ & & & & .74 \\
\hline Underweight or normal $\left(<25 \mathrm{~kg} / \mathrm{m}^{2}\right)$ & $154(17.6)$ & $75(17.1)$ & $79(18.2)$ & \\
\hline Overweight $\left(\geq 25\right.$ and $\left.<30 \mathrm{~kg} / \mathrm{m}^{2}\right)$ & $239(27.3)$ & $125(28.4)$ & $114(26.2)$ & \\
\hline Obese $\left(\geq 30 \mathrm{~kg} / \mathrm{m}^{2}\right)$ & $482(55.1)$ & $240(54.6)$ & $242(55.6)$ & \\
\hline Smoking status, n (\%) & & & & .003 \\
\hline Never & $466(53.3)$ & $255(58.0)$ & $211(48.5)$ & \\
\hline Former & $215(24.6)$ & $107(24.3)$ & $108(24.8)$ & \\
\hline Current & $194(22.2)$ & $78(17.7)$ & $116(26.7)$ & \\
\hline
\end{tabular}

FIT, fecal immunochemical test.

$P$ values compare participants who returned and did not return FIT. $P$ values were generated from $\chi^{2}$ tests for categorical variables and bold font indicates statistical significance at the two-sided $\alpha=0.05$ level.

$(63.2 \%)$ were female and the mean $[\mathrm{SD}]$ age was 59 [7.11] years. Most patients ( $\mathrm{n}=392 ; 44.8 \%)$ were Hispanic/Latino, one quarter $(\mathrm{n}=213 ; 24.3 \%)$ were non-Hispanic black, and almost one third ( $\mathrm{n}=259 ; 29.5 \%)$ were non-Hispanic white. Most patients were self payers $(n=415 ; 47.4 \%)$. Mean [SD] BMI was 30.90 [7.76] $\mathrm{kg} / \mathrm{m}^{2}$ and over half $(\mathrm{n}=482 ; 55.1 \%)$ were defined as obese. Approximately one quarter were current smokers $(\mathrm{n}=194$; $22.2 \%)$. Patients who returned the FIT $(\mathrm{n}=440)$ were comparable to patients who did not return the FIT $(n=435)$ in terms of sex, insurance status, and $\mathrm{BMI}$, but nonreturners were more likely to identify as non-Hispanic black and more likely to be current smokers. See Table 1 for more detail.

Patients who identified as non-Hispanic black had a marginally increased risk of FIT nonreturn $(\mathrm{RR}=1.18[95 \% \mathrm{CI}, 0.99,1.40])$ and patients who identified as non-Hispanic other had an increased risk of FIT nonreturn (RR $=1.49$ [95\% CI, 1.022.19]) compared with non-Hispanic white patients.
Patients with public insurance were at increased risk of FIT nonreturn compared with patients with private insurance $(\mathrm{RR}=1.21$ [95\% CI, 1.01-1.44]). Self-payers, including those who paid a discounted fee based on a sliding scale, had a lower risk of FIT nonreturn compared with patients with private insurance $(\mathrm{RR}=0.85$ [95\% CI, 0.73-0.99]). Current smokers were at increased risk of FIT nonreturn compared with never smokers $(\mathrm{RR}=1.32[95 \%$ CI, 1.13-1.54]). After adjusting for all patient characteristics in multivariate models, current smokers remained at increased risk for FIT nonreturn (Table 2).

Among patients who did not return the FIT $(\mathrm{n}=435), 121$ patients participated in a telephone survey. The 121 patients who participated in the survey were less likely to identify as non-Hispanic black but were otherwise similar to patients who did not participate in terms of age, sex, insurance status, BMI, and smoking status (results not shown). The most common barriers to FIT return 
Table 2. Bivariate and Multivariate Risk Ratios (RR [95\% CI $]$ ) to Evaluate the Association Between Patient Characteristics and FIT Non-Return, $\mathrm{n}=875$

\begin{tabular}{|c|c|c|c|c|c|c|}
\hline & \multicolumn{3}{|c|}{ Bivariate } & \multicolumn{3}{|c|}{ Multivariate } \\
\hline & $\mathrm{RR}$ & $95 \% \mathrm{CI}$ & $P$ & $\mathrm{RR}$ & $95 \% \mathrm{CI}$ & $P$ \\
\hline \multicolumn{7}{|l|}{ Sex } \\
\hline Male (Ref) & 1.00 & - & & 1.00 & - & \\
\hline Female & 0.93 & $0.82,1.07$ & .33 & 0.95 & $0.82,1.09$ & .43 \\
\hline \multicolumn{7}{|l|}{ Age, years } \\
\hline 50 to 59 years & 1.11 & $0.86,1.45$ & .42 & 1.09 & $0.83,1.43$ & .52 \\
\hline 60 to 69 years & 0.98 & $0.74,1.29$ & .88 & 0.96 & $0.73,1.27$ & .79 \\
\hline 70 years and older (Ref) & 1.00 & - & & 1.00 & - & \\
\hline \multicolumn{7}{|l|}{ Race/ethnicity } \\
\hline Hispanic or Latino & 0.94 & $0.80,1.11$ & .45 & 1.01 & $0.84,1.20$ & .94 \\
\hline Non-Hispanic white (Ref) & 1.00 & - & & 1.00 & - & \\
\hline Non-Hispanic black & 1.18 & $0.99,1.40$ & .06 & 1.16 & $0.98,1.38$ & .08 \\
\hline Non-Hispanic other & 1.49 & $1.02,2.19$ & .04 & 1.23 & $0.85,1.80$ & .26 \\
\hline \multicolumn{7}{|l|}{ Insurance status } \\
\hline Private (Ref) & 1.00 & - & & 1.00 & - & \\
\hline Public & 1.21 & $1.01,1.44$ & .04 & 1.01 & $0.85,1.19$ & .95 \\
\hline Self-pay & 0.85 & $0.73,0.99$ & .04 & 1.13 & $0.94,1.35$ & .18 \\
\hline \multicolumn{7}{|l|}{ Body mass index } \\
\hline Underweight or normal (Ref) & 1.00 & - & & 1.00 & - & \\
\hline Overweight & 0.93 & $0.76,1.14$ & .48 & 0.97 & $0.79,1.19$ & .79 \\
\hline Obese & 0.98 & $0.82,1.17$ & .81 & 1.03 & $0.86,1.24$ & .71 \\
\hline \multicolumn{7}{|l|}{ Smoking } \\
\hline Never (Ref) & 1.00 & - & & 1.00 & - & \\
\hline Former & 1.11 & $0.94,1.31$ & .22 & 1.06 & $0.89,1.26$ & .50 \\
\hline Current & 1.32 & $1.13,1.54$ & $<.001$ & 1.26 & $1.07,1.48$ & .01 \\
\hline
\end{tabular}

CI, confidence interval; FIT, fecal immunochemical test; RR, risk ratio.

Bivariate and multivariate log-binomial regression models the risk of FIT non-return. Multivariate model includes all variables in the table. Risk ratios greater than one indicate the patient characteristic is a risk factor for failing to return the FIT and risk ratios less than one indicate a beneficial characteristic for FIT return. Bold font indicates statistical significance at the two-sided $\alpha=0.05$ level.

reported by patients were forgetfulness (61\%), lack of motivation $(51 \%)$, and fear of embarrassment (31\%). Clinicians perceived the most common patient barriers to FIT return were lack of motivation (81\%), forgetfulness (61\%), fear of embarrassment (55\%), and FIT instructions (55\%). Patients reported that prepaid postage with return address on FIT return envelopes (77\%), live call reminders (73\%), and reminders by text message $(60 \%)$ would be helpful to FIT return. Clinicians reported that prepaid postage envelopes with return address (71\%), live call reminders (52\%), and better FIT instructions (45\%) would be helpful to increase patient FIT return (Table 3).

We compared FIT barriers and facilitators by insurance status, race/ethnicity, and language preference. Patients who participated in the telephone survey $(\mathrm{n}=121)$ were privately insured $(\mathrm{n}=30$;
$25 \%$ ), publicly insured ( $\mathrm{n}=26 ; 21 \%)$, or self payers $(n=65 ; 54 \%)$. There were no statistically significant differences in barriers and facilitators between insurance groups, with the exception of live call reminders to facilitate FIT return: 23 patients with private insurance $(77 \%$ of the 30 patients with private insurance), 13 patients with public insurance $(50 \%$ of the 26 patients with public insurance), and 52 self payers ( $80 \%$ of the 65 selfpay patients; $P=.03$ across groups) preferred live call reminders. Patients who participated in the telephone survey were Hispanic/Latino ( $\mathrm{n}=48$; $40 \%$ of the 121 telephone participants), non-Hispanic black $(\mathrm{n}=28 ; 23 \%$ of the 121 telephone participants), and non-Hispanic white ( $\mathrm{n}=45$; $37 \%$ of the 121 telephone participants); there were 94 (78\% of the 121 telephone participants) English speakers and 27 (22\% of the 121 telephone partic- 
Table 3. Barriers and Facilitators of FIT Return for Patients and Clinicians

\begin{tabular}{|c|c|c|}
\hline & $\begin{array}{l}\text { Patients, } \mathrm{n}(\%) \\
\quad(\mathrm{n}=121)\end{array}$ & $\begin{array}{c}\text { Clinicians, } \mathrm{n}(\%) \\
\quad(\mathrm{n}=31)\end{array}$ \\
\hline \multicolumn{3}{|l|}{ Barriers } \\
\hline Cost of test & $22(18)$ & $3(10)$ \\
\hline Poor/confusing test instructions & $33(27)$ & $17(55)$ \\
\hline Transportation to return site & $23(19)$ & $13(42)$ \\
\hline Time to complete test & $26(21)$ & $1(3)$ \\
\hline Limited return sites & $13(11)$ & $0(0)$ \\
\hline Return site hours of operation & $3(2)$ & $2(6)$ \\
\hline Fear of abnormal findings & $24(20)$ & $7(23)$ \\
\hline Fear of embarrassment & $38(31)$ & $17(55)$ \\
\hline Lack of motivation & $62(51)$ & $25(81)$ \\
\hline Forgetfulness & $74(61)$ & $19(61)$ \\
\hline \multicolumn{3}{|l|}{ Facilitators } \\
\hline Pre-paid postage w/ return address & $93(77)$ & $22(71)$ \\
\hline More drop-off sites & $63(52)$ & $6(19)$ \\
\hline Live call reminders & $88(73)$ & $16(52)$ \\
\hline Text message reminders & $72(60)$ & $8(26)$ \\
\hline Email reminders & $34(28)$ & $11(35)$ \\
\hline Mailed reminders & $51(42)$ & $4(13)$ \\
\hline Better test instructions & $33(27)$ & $14(45)$ \\
\hline More educational materials & $64(53)$ & $4(13)$ \\
\hline More time with clinician & $61(50)$ & $9(29)$ \\
\hline Automatic messaging by EPIC & $\mathrm{n} / \mathrm{a}$ & $4(13)$ \\
\hline
\end{tabular}

FIT, fecal immunochemical test.

Patients self-reported barriers and facilitators by telephone survey and clinicians reported perceived patient barriers and facilitators by online survey. Both patients and clinicians could select as many barriers and facilitators as they deemed appropriate.

ipants) Spanish speakers. Race/ethnicity and language preference demonstrated similar patterns of FIT return barriers and facilitators (Tables 4 and 5). Of note, Hispanic/Latino patients and Spanishspeaking patients were more likely to report test instructions as a barrier to the FIT, and more likely to report better test instructions, more educational materials, and more time with their clinician as FIT facilitators (Table 4 and Table 5).

Finally, we identified clinician-preferred colorectal cancer screening methods. Almost all $(\mathrm{n}=$ $30 ; 97 \%$ of the 31 participating) clinicians reported they would recommend a colonoscopy for insured patients, and 21 (68\% of the 31 participating) clinicians would recommend stool-based tests (FITs and gFOBTs) for uninsured patients.

\section{Discussion}

Multiple studies have identified the importance of a physician recommendation for colorectal cancer screening. ${ }^{28,29}$ The purpose of our study was to compare, subsequent to a clinician recommenda- tion, patients at a federally qualified health center who did and did not participate in FIT for colorectal cancer screening. In our 6-month study of a large, racially/ethnically diverse clinic population, 875 patients received orders for FITs and the return rate was approximately $50 \%$. Patients who were current smokers were at increased risk for failure to return the FIT, but there were no differences between returners and nonreturners in terms of sex, race/ethnicity, insurance status, and BMI. Our findings regarding poor screening adherence among current smokers is consistent with other work. ${ }^{16,30}$ A growing body of evidence suggests that cancer screening settings may be a "teachable moment" for multiple lifestyle interventions, including increasing physical activity and healthy diet, alcohol consumption reduction, and smoking cessation. $^{31,32}$ Our findings regarding smoking may be particularly useful for primary care providers to identify and maximize person-centered clinical care opportunities and use strategies such as motivational interviewing to support patients with dual 
Table 4. Reported Barriers and Facilitators of FIT Return by Patient Race/Ethnicity

\begin{tabular}{|c|c|c|c|c|}
\hline & $\begin{array}{l}\text { Hispanic or } \\
\text { Latino, n (\%) } \\
(\mathrm{n}=48)\end{array}$ & $\begin{array}{l}\text { Non-Hispanic } \\
\text { Black, n (\%) } \\
(\mathrm{n}=28)\end{array}$ & $\begin{array}{l}\text { Non-Hispanic } \\
\text { White, } \mathrm{n}(\%) \\
(\mathrm{n}=45)\end{array}$ & $P$ \\
\hline \multicolumn{5}{|l|}{ Barriers } \\
\hline Cost of test & $6(13)$ & $6(21)$ & $10(22)$ & .39 \\
\hline Poor/confusing test instructions & $26(54)$ & $4(14)$ & $3(7)$ & $<.001$ \\
\hline Transportation to return site & $12(25)$ & $4(14)$ & $7(16)$ & .42 \\
\hline Time to complete test & $11(23)$ & $6(21)$ & $9(20)$ & .96 \\
\hline Limited return sites & $3(6)$ & $2(7)$ & $8(18)$ & .18 \\
\hline Return site hours of operation & $1(2)$ & $0(0)$ & $2(4)$ & .61 \\
\hline Fear of abnormal findings & $10(21)$ & $7(25)$ & $7(16)$ & .56 \\
\hline Fear of embarrassment & $27(56)$ & $5(18)$ & $6(13)$ & $<.001$ \\
\hline Lack of motivation & $32(67)$ & $14(50)$ & $16(36)$ & .03 \\
\hline Forgetfulness & $35(73)$ & $19(68)$ & $20(44)$ & .02 \\
\hline \multicolumn{5}{|l|}{ Facilitators } \\
\hline Pre-paid postage w/ return address & $40(83)$ & $16(57)$ & $37(82)$ & .05 \\
\hline More drop-off sites & $31(65)$ & $16(57)$ & $16(36)$ & .02 \\
\hline Live call reminders & $40(83)$ & $19(68)$ & $29(64)$ & .13 \\
\hline Text message reminders & $29(60)$ & $17(61)$ & $26(58)$ & .84 \\
\hline Email reminders & $12(25)$ & $9(32)$ & $13(29)$ & .57 \\
\hline Mailed reminders & $23(48)$ & $12(43)$ & $16(36)$ & .49 \\
\hline Better test instructions & $26(54)$ & $4(14)$ & $3(7)$ & $<.001$ \\
\hline More educational materials & $36(75)$ & $14(50)$ & $14(31)$ & $<.001$ \\
\hline More time with clinician & $34(71)$ & $13(46)$ & $14(31)$ & $<.001$ \\
\hline
\end{tabular}

FIT, fecal immunochemical test.

$P$ values generated from $\chi^{2}$ tests. Bold font indicates statistical significance at the two-sided $\alpha=0.05$ level.

lifestyle changes regarding smoking and cancer screening.

The Health Belief Model is a commonly used framework to explain cancer screening behavior and posits that education and knowledge may modify the pathway between individual perceptions (eg, perceived susceptibility of the disease) and behavior. ${ }^{33}$ The clinician plays a key role in patient behavior through advising, communicating, and educating the patient. Clinician-patient interactions regarding preventive services should follow the 5A's: assess, advise, agree, assist, and arrange. ${ }^{34}$ In our study, most clinicians reported they would advise insured patients to receive a colonoscopy and uninsured patients to receive stool-based screening tests. Physician preferences for colonoscopies have been noted throughout the literature, ${ }^{4-8}$ but the USPSTF equally endorses multiple colorectal cancer screening options. Education for the patient on the benefits, harms, and alternatives for each colorectal cancer screening modality may engage patients in the shared decision making process and increase screening adherence, particularly for race/ ethnic minority patients. ${ }^{33}$
Recent evidence suggests that colorectal cancer mortality has increased since 2005 among those aged 40 to 54 years, ${ }^{35}$ and in May 2018, the American Cancer Society expanded its colorectal cancer screening recommendations to begin screening at 45 years of age. ${ }^{36}$ In our study of patients aged $\geq 50$ years, younger individuals appeared to be at a marginally increased risk of FIT return failure, and although results were not statistically significant, this is consistent with other recent work ${ }^{13}$ and troubling in light of trend data. In our study, we did not observe differences in patient-reported barriers or facilitators of FIT return between age strata (results not shown). More work is needed to understand why younger individuals in the United States are less likely to be screened and to develop strategies to increase motivation to be screened, which we noted as a common barrier to colorectal cancer screening in all ages. Large-scale education efforts at the societal level may be needed to educate the public to increase colorectal cancer screening motivation among midlife adults in their fifth (40 to 49 years) and sixth (50 to 59 years) decades of life. 
Table 5. Reported Barriers and Facilitators of FIT Return by Patient Language

\begin{tabular}{|c|c|c|c|}
\hline & $\begin{array}{l}\text { Spanish, } \mathrm{n}(\%) \\
(\mathrm{n}=27)\end{array}$ & $\begin{array}{c}\text { English, } \mathrm{n}(\%) \\
(\mathrm{n}=94)\end{array}$ & $P$ \\
\hline \multicolumn{4}{|l|}{ Barriers } \\
\hline Cost of test & $4(15)$ & $18(19)$ & .78 \\
\hline Poor/confusing test instructions & $22(81)$ & $11(12)$ & $<.001$ \\
\hline Transportation to return site & $8(30)$ & $15(16)$ & .16 \\
\hline Time to complete test & $9(33)$ & $17(18)$ & .12 \\
\hline Limited return sites & $1(4)$ & $12(13)$ & .29 \\
\hline Return site hours of operation & $0(0)$ & $3(3)$ & .99 \\
\hline Fear of abnormal findings & $5(19)$ & $19(20)$ & .79 \\
\hline Fear of embarrassment & $22(81)$ & $16(17)$ & $<.001$ \\
\hline Lack of motivation & $26(96)$ & $36(38)$ & $<.001$ \\
\hline Forgetfulness & $26(96)$ & $48(51)$ & $<.001$ \\
\hline \multicolumn{4}{|l|}{ Facilitators, n (\%) } \\
\hline Pre-paid postage w/ return address & $26(96)$ & $67(71)$ & $<.001$ \\
\hline More drop-off sites & $23(85)$ & $40(43)$ & $<.001$ \\
\hline Live call reminders & $26(96)$ & $62(66)$ & $<.001$ \\
\hline Text message reminders & $17(63)$ & $55(59)$ & .82 \\
\hline Email reminders & $3(11)$ & $31(33)$ & .06 \\
\hline Mailed reminders & $11(41)$ & $40(43)$ & .99 \\
\hline Better test instructions & $22(81)$ & $11(12)$ & $<.001$ \\
\hline More educational materials & $26(96)$ & $38(40)$ & $<.001$ \\
\hline More time with clinician & $23(85)$ & $38(40)$ & $<.001$ \\
\hline
\end{tabular}

FIT, fecal immunochemical test.

$P$ values generated from $\chi^{2}$ tests. Bold font indicates statistical significance at the two-sided $\alpha=0.05$ level.

Among those who did not return the FIT, patients reported that prepaid postage with return addresses on the FIT kit return envelope and live call reminders would facilitate FIT kit return. These facilitators were similar for all race/ethnic groups. Hispanic/Latino patients, and Spanish speakers in particular, were more likely to indicate that better test instructions, more educational materials, and more time with the clinician during their clinic visit would facilitate FIT return. In our study, although there were no race/ethnic differences in FIT return in the multivariate models, Hispanic/Latino patients were significantly more likely to report poor/confusing test instructions and fear of embarrassment as barriers to FIT screening. This is concordant with recent qualitative work among Hispanic/Latino patients by Leal et $\mathrm{al},{ }^{37}$ who noted beliefs about illness and health, and reactions to illness such as embarrassment and fear, were major themes that limited the early detection and treatment of colorectal cancer among lower-income, minority patients. Several studies have also noted the use of bilingual community health workers, or promotoras de salud, in colorectal cancer screening interventions. ${ }^{38}$ Promotoras are generally trained community members that connect community members to research or formal institutions through culturally targeted interventions. $^{39}$ The large disparities we noted in our study between English-speaking patients and Spanishspeaking patients may represent an opportunity to tailor patient care with bilingual community health workers or patient navigators in the future.

There are several limitations of our study. Approximately one quarter of patients $(n=121 ; 28 \%$ of the 435 nonreturners) who did not return the FIT participated in a telephone interview. In our patient population, many patients had inaccurate or out of service telephone numbers in their medical records, despite clinic protocol focused on updating this information at every clinical encounter. Although our response rate was lower than desired, the Pew Research Center has reported that response rates for telephone surveys have plateaued at approximately $9 \%$, roughly 25 percentage points less than in $1997 .{ }^{40}$ Selection bias may have occurred, such that survey participants may have differed from nonparticipants. Indeed, patient partic- 
ipants who completed the telephone survey in our study were less likely to be non-Hispanic black, but nonreturners who participated in the telephone survey were otherwise similar to nonreturners who did not participate in the telephone survey in terms of age, sex, insurance status, BMI, and smoking status. Future work should consider multiple survey modalities to increase participation. Although the telephone survey was confidential, some patients may have felt uncomfortable with the personal nature of the questions and thus underreported or misreported true barriers. For example, we did not have any patients report disgust by the idea of handling stool, but another study reported that approximately $20 \%$ of 82 patients who did not complete FIT testing reported disgust. ${ }^{21}$ In addition, we did not collect information about possible clinical presentations that may have initiated a FIT or other colorectal examination. Although we excluded patients younger than 50 years of age to mitigate FIT workups for reasons other than general screening, it is possible that some patients may have presented with clinically relevant signs or have been ineligible for other screening methods. Finally, during the telephone survey, several patients whose medical records showed a FIT order stated that they did not receive a kit to take home, which may have slightly underestimated the FIT return rate in our clinic.

Nevertheless, findings from this research study benefited patient care in our clinic by identifying procedural glitches that were easily addressed and increased the overall screening rate from $28 \%$ to $35 \%$ within 6 months. For example, some clinicians were unaware that patients could return FIT kits via mail, so we created a brief physician training to increase clinician awareness and improve the assist/ arrange phase of preventive care decision making between health care providers and patients. In addition, a review of clinic procedure following this study found that many providers relied on Spanishspeaking staff to orally dictate FIT instructions at the clinic visit, which may be the reason that that many Hispanic/Latino patients did not feel informed about test instructions. While Spanish-language test instructions have been available, many clinicians and nurses were unsure of where to locate them. Currently, we are working with our information technology team to auto-populate Spanish language instructions in the electronic medical record check-out paperwork whenever the patient's primary language is marked as Spanish. Strategies such as leveraging health information technology, optimizing team work, education to both patients and clinicians, use of patient navigators, and interactive workshops for clinician training have been shown to increase colorectal cancer screening in other primary care settings. ${ }^{41}$

\section{Conclusion}

The prevention of colorectal cancer in low-income, minority patient populations is multifaceted. Racial/ethnic minorities and Spanish speakers experience significant barriers to FIT return compared with their English-speaking, non-Hispanic white counterparts. Tailored interventions may maximize FIT return and increase colorectal cancer screening rates in resource-limited community health centers across the nation. Understanding patient and clinician perspectives for colorectal cancer screening may be an important step to increase screening rates and thereby identify early-stage cancer. Bilingual community health workers may increase screening rates by serving as patient navigators, providing live call reminders to patients, and mitigating psychosocial factors such as fear and embarrassment with culturally appropriate interventions. Disseminating accurate information to clinicians may increase awareness about colorectal cancer screening modalities and clinic-specific screening workflow processes. Given recent data about colorectal cancer incidence and mortality for race/ethnic minority groups and adults aged 40 to 54 years, these tailored education and intervention efforts for both clinicians and patients may increase cancer screening adherence among adults across the life course.

To see this article online, please go to: http://jabfm.org/content/ 32/2/180.full.

\section{References}

1. Siegel RL, Miller KD, Fedewa SA, et al. Colorectal cancer statistics, 2017: Colorectal cancer statistics, 2017. CA Cancer J Clin 2017;67:177-193.

2. Jackson CS, Oman M, Patel AM, Vega KJ. Health disparities in colorectal cancer among racial and ethnic minorities in the United States. J Gastrointest Oncol 2016;7(Suppl 1):S32-S43.

3. US Preventive Services Task Force, Bibbins-Domingo K, Grossman DC, et al. Screening for colorectal cancer: US Preventive Services Task Force recommendation statement. JAMA 2016;315:25642575 . 
4. Brown T, Lee JY, Park J, et al. Colorectal cancer screening at community health centers: A survey of clinicians' attitudes, practices, and perceived barriers. Prev Med Rep 2015;2:886-891.

5. Feeley TH, Cooper J, Foels T, Mahoney MC. Efficacy expectations for colorectal cancer screening in primary care: Identifying barriers and facilitators for patients and clinicians. Health Commun 2009;24: 304-315.

6. Hoffman RM, Rhyne RL, Helitzer DL, et al. Barriers to colorectal cancer screening: Physician and general population perspectives, New Mexico, 2006. Prev Chronic Dis 2011;8:A35.

7. Klabunde CN, Lanier D, Nadel MR, McLeod C, Yuan G, Vernon SW. Colorectal cancer screening by primary care physicians: recommendations and practices, 2006-2007. Am J Prev Med 2009;37:8-16.

8. Guerra CE, Schwartz JS, Armstrong K, Brown JS, Halbert CH, Shea JA. Barriers of and facilitators to physician recommendation of colorectal cancer screening. J Gen Intern Med 2007;22:1681-1688.

9. Hoover S, Subramanian S, Tangka FKL, et al. Patients and caregivers costs for colonoscopy-based colorectal cancer screening: Experience of low-income individuals undergoing free colonoscopies. Eval Program Plann 2017;62:81-86.

10. de Moor JS, Cohen RA, Shapiro JA, et al. Colorectal cancer screening in the United States: Trends from 2008 to 2015 and variation by health insurance coverage. Prev Med 2018;112:199-206.

11. Healthy People 2020. C-16: Increase the proportion of adults who receive a colorectal screening based on most recent guidelines. Available from: https:// www.healthypeople.gov/2020/data-search/Searchthe-Data\#objid=4054. Accessed May 15, 2018.

12. National Colorectal Cancer Roundtable. CRC screening rates reach 39.9\% in FQHCs in 2016. Available from: http://nccrt.org/2016-uds-rates/. Accessed May 15, 2018.

13. van der Vlugt M, Grobbee EJ, Bossuyt PM, et al. Adherence to colorectal cancer screening: Four rounds of faecal immunochemical test-based screening. Br J Cancer 2017;116:44-49.

14. Family Health Center. 2016 Vision \& Fact Sheet. Main Clinic and Administrative Site, Waco, TX. May 2016. Available from: https://www.tachc.org.

15. Seibert RG, Hanchate AD, Berz JP, Schroy PC 3rd. National disparities in colorectal cancer screening among obese adults. Am J Prev Med 2017;53(2):e41e49.

16. Carlos RC, Underwood W 3rd, Fendrick AM, Bernstein SJ. Behavioral associations between prostate and colon cancer screening. J Am Coll Surg 2005; 200:216-223.

17. Wang J, Moehring J, Stuhr S, Krug M. Barriers to colorectal cancer screening in Hispanics in the United States: An integrative review. Appl Nurs Res $2013 ; 26: 218-224$.
18. Coronado GD, Schneider JL, Sanchez JJ, Petrik AF, Green B. Reasons for non-response to a directmailed FIT kit program: Lessons learned from a pragmatic colorectal-cancer screening study in a federally sponsored health center. Transl Behav Med 2015;5:60-67.

19. Greiner KA, Geana MV, Epp A, et al. A computerized intervention to promote colorectal cancer screening for underserved populations: Theoretical background and algorithm development. Technol Health Care 2012;20:25-35.

20. Khankari K, Eder M, Osborn CY, et al. Improving colorectal cancer screening among the medically underserved: A Pilot study within a federally qualified health center. J Gen Intern Med 2007;22:14101414.

21. Quick BW, Hester CM, Young KL, Greiner KA. Self-reported barriers to colorectal cancer screening in a racially diverse, low-income study population. J Community Health 2013;38:285-292.

22. Briant KJ, Espinoza N, Galvan A, et al. An innovative strategy to reach the underserved for colorectal cancer screening. J Cancer Educ 2015;30:237-243.

23. Tu SP, Taylor V, Yasui Y, et al. Promoting culturally appropriate colorectal cancer screening through a health educator: A randomized controlled trial. Cancer 2006;107:959-966.

24. Cole AM, Tu SP, Fernandez ME, Calo WA, Hotz J, Wolver S. Reported use of electronic health records to implement evidence based approaches to colorectal cancer screening in community health centers. J Health Care Poor Underserved 2015;26:12351245 .

25. Gwede CK, Davis SN, Quinn GP, et al. Making it work: Health care provider perspectives on strategies to increase colorectal cancer screening in federally qualified health centers. J Cancer Educ 2013;28:777783.

26. Bynum SA, Davis JL, Green BL, Katz RV. Unwillingness to participate in colorectal cancer screening: Examining fears, attitudes, and medical mistrust in an ethnically diverse sample of adults 50 years and older. Am J Health Promot 2012;26:295-300.

27. Spiegelman D, Hertzmark E. Easy SAS calculations for risk or prevalence ratios and differences. Am J Epidemiol 2005;162:199-200.

28. Guessous I, Dash C, Lapin P, Doroshenk M, Smith RA, Klabunde CN. Colorectal cancer screening barriers and facilitators in older persons. Prev Med 2010;50(1-2):3-10.

29. Beydoun HA, Beydoun MA. Predictors of colorectal cancer screening behaviors among average-risk older adults in the United States. Cancer Causes Control 2008;19:339-359.

30. Stevens C, Smith SG, Vrinten C, Waller J, Beeken RJ. Lifestyle changes associated with participation in colorectal cancer screening: Prospective data from the English Longitudinal Study of Ageing. J Med 
Screen 2018;969141318803973 [Epub ahead of print].

31. Robb KA, Power E, Kralj-Hans I, Atkin WS, Wardle J. The impact of individually-tailored lifestyle advice in the colorectal cancer screening context: A randomised pilot study in North-West London. Prev Med 2010;51:505-508.

32. Lee AS, Ozakinci G, Leung S, Humphris G, Dale H, Hamlet N. Lifestyle change in the cancer setting using 'the teachable moment': Protocol for a proofof-concept pilot in a urology service. Pilot Feasibility Stud 2016;2:65; eCollection 2016.

33. Christy SM, Rawl SM. Shared decision-making about colorectal cancer screening: A conceptual framework to guide research. Patient Educ Couns 2013;91:310-317.

34. Lafata JE, Cooper GS, Divine G, et al. Patientphysician colorectal cancer screening discussions: Delivery of the 5A's in practice. Am J Prev Med 2011;41:480-486.

35. Siegel RL, Miller KD, Jemal A. Colorectal cancer mortality rates in adults aged 20 to 54 years in the United States, 1970-2014. JAMA 2017;318:572574.

36. Wolf AMD, Fontham ETH, Church TR, et al. Colorectal cancer screening for average-risk adults:
2018 guideline update from the American Cancer Society. CA Cancer J Clin 2018;68:250-281.

37. Leal IM, Kao LS, Karanjawala B, Escamilla RJ, Ko TC, Millas SG. Understanding patients' experiences of diagnosis and treatment of advanced colorectal cancer in a safety-net hospital system: A qualitative study. Dis Colon Rectum 2018;61:504-513.

38. Gonzalez SA, Ziebarth TH, Wang J, Noor AB, Springer DL. Interventions promoting colorectal cancer screening in the Hispanic population: A review of the literature. J Nurs Scholarsh 2012;44:332340.

39. Reinschmidt KM, Hunter JB, Fernández ML, LacyMartínez CR, Guernsey de Zapien J, Meister J. Understanding the success of promotoras in increasing chronic diseases screening. J Health Care Poor Underserved 2006;17:256-264.

40. Pew Research Center. What low response rates mean for telephone surveys. May 15, 2017. Available from: http://www.pewresearch.org/2017/05/15/whatlow-response-rates-mean-for-telephone-surveys/. Accessed May 15, 2018.

41. Bakhai S, Ahluwalia G, Nallapeta N, Mangat A, Reynolds JL. Faecal immunochemical testing implementation to increase colorectal cancer screening in primary care. BMJ Open Qual 2018;7(4):e000400. 